\title{
P81 Antibody to Cardiotonic Steroid Reduces Blood Pressure and Vascular Fibrosis in Preeclampsia
}

\author{
NI Agalakova ${ }^{3}$, VA Reznik ${ }^{1}$, OV Nadei ${ }^{3}$, IA Ershov ${ }^{1}$, OS Rassokha ${ }^{1}$, ML Vasyutina $^{2}$, MM Galagudza $^{2}$, AY Bagrov ${ }^{1,3 *}$ \\ ${ }^{1}$ Department of Obstetrics and Gynecology, School of Pediatric Medicine \\ ${ }_{2}^{2}$ Institute of Experimental Medicine, Almazov National Medical Research Centre \\ ${ }^{3}$ Sechenov Institute of Evolutionary Physiology and Biochemistry, St. Petersburg, Russia
}

\section{ABSTRACT}

Background: Previous studies implicated cardiotonic steroids, including Na/K-ATPase inhibitor marinobufagenin (MBG), in the pathogenesis of preeclampsia (PE). We demonstrated that MBG induces fibrosis via mechanism involving inhibition of Fli1, a nuclear transcription factor and a negative regulator of collagen-1 synthesis.

Objectives and Methods: We hypothesized that PE blockade of increased MBG with antibody would lessen the fibrosis of umbilical arteries and lower the blood pressure in rats with PE. We tested 36 pregnant Sprague-Dawley rats in which 12 were made hypertensive by $1.8 \% \mathrm{Na}$ supplementation (days 6-19 of gestation), 12 pregnant rats served controls. At day 19, PE rats received one intraperitoneal injection of polyclonal anti-MBG-4 antibody $(0.5 \mathrm{ug} / \mathrm{mL})$ for 4 hours.

Results: PE was associated with higher blood pressure (117 \pm 2 vs $107 \pm 2 \mathrm{mmHg} ; p<0.01)$, plasma MBG levels $(1.54 \pm 0.34$ vs $0.49 \pm 0.11 \mathrm{nmol} / \mathrm{L} ; p<0.01$ ), protein excretion ( $26 \mathrm{vs} 12 \mathrm{mg} / 24$ hours), sFlt-1 (4-fold), decrease in Fli1 (7-fold) and increase in collagen-1 in aorta (4-fold) vs. control rats (all $p<0.01$ ). In 12 rats was treated with polyclonal anti-MBG-4 antibody blood pressure dropped ( $93 \pm 3 \mathrm{mmHg}$ ) and Fli1 was decreased much less (2-fold; $p<0.01$ vs nontreated rats).

Conclusion: These results demonstrate that in experimental PE elevated MBG level is implicated in umbilical fibrosis via suppression of Fli1. Supported by Russian Scientific Foundation grant № 18-15-00222.

(C) 2019 Association for Research into Arterial Structure and Physiology. Publishing services by Atlantis Press International B.V.

This is an open access article distributed under the CC BY-NC 4.0 license (http://creativecommons.org/licenses/by-nc/4.0/). 